\title{
CHANGES OF VITAMINS B1, B12 AS PREDICTING FACTORS OF PERIPHERAL POLYNEUROPATHY IN PULMONARY TUBERCULOSIS PATIENTS
}

\author{
Olga M. SHVETS ${ }^{1}$, Olga S. SHEVCHENKO ${ }^{1}$, Liliia D. TODORIKO ${ }^{2 凶,}$ \\ Olena L. TOVAZHNYANSKA ${ }^{1}$, Olga I. DUBYNSKA ${ }^{1}$, Mykola M. OSTROVSKYI ${ }^{3}$, \\ Iryna Ya. MAKOYDA ${ }^{3}$, Inga V. YEREMENCHUK ${ }^{2}$ \\ ${ }^{1}$ Kharkiv National Medical University, Kharkiv, Ukraine \\ ${ }^{2}$ Higher State Educational Establishment of Ukraine "Bukovinian State Medical University", Chernivtsi, \\ Ukraine \\ ${ }^{3}$ Ivano-Frankivsk National Medical University, Ivano-Frankivsk, Ukraine
}

Received 04 Dec 2019, Accepted 28 Jan 2020

https://doi.org/10.31688/ABMU.2020.55.1.13

\section{Abstract}

The objective of the study was to assess the development of peripheral neuropathy in patients with newly diagnosed pulmonary tuberculosis during the treatment with first- and second-line antitubercular drugs, by studying the changes of plasma vitamin B1 and vitamin B12 levels.

Materials and methods. The study involved $22 \mathrm{pa}-$ tients with drug-susceptible tuberculosis who received a standard four-component regimen that included isoniazid and 26 patients with drug-resistant tuberculosis whose treatment regimen included linezolid. Twenty matched control patients were included for baseline assessment comparison. Plasma vitamin B1 (thiamine) and plasma vitamin B12 (cyanocobalamin) levels were studied in all patients before treatment and after 30 days of antituberculosis therapy. To identify changes of the peripheral nervous system, we performed stimulation electroneuromyography (ENMG) on the lower limbs. The following factors were evaluated: motor

\section{Résumé}

La dynamique des vitamines B1 et B12 en tant que prediction de neuropathie périphérique chez les patients atteints de tuberculose pulmonaire

Le but de l'étude est de pronostiquer l'évolution de la neuropathie périphérique en étudiant la dynamique des taux de vitamines B1 et B12 chez les patients atteints d'une tuberculose pulmonaire nouvellement diagnostiquée lors d'un traitement par des antituberculeux de première et de deuxième ligne.

Matériels et méthodes. L'étude portait sur 22 patients atteints de tuberculose sensible et recevant un schéma thérapeutique standard à 4 composants incluant de l'isoniazide et 26 patients atteints de tuberculose résistante aux médicaments dont le schéma thérapeutique comprenait du linézolide. Le groupe témoin - 20 individus en bonne santé. Les taux plasmatiques de vitamines B1 et B12 ont été étudiés chez tous les patients avant le traitement et après 30 jours 
nerve conduction velocity (MNCV), terminal motor latency (TML), sensory nerve conduction velocity (SNCV) and terminal sensory latency (TSL).

Results. Patients with newly diagnosed pulmonary tuberculosis (TB) had lower initial plasma levels of vitamins B1 and B12, compared to age- and sex-matched healthy persons. We did not find significant changes in vitamin B status and electroneuromyography during the treatment with combinations of isoniazid and first-line anti-TB drugs. During the treatment with combinations of linezolid and second-line anti-TB drugs, we identified significant decreases of plasma vitamin B1 and B12 levels and worsening of electroneuromyography indices by sensory and motor fibers.

Conclusions. The deficiency of vitamins B1 and B12 during treatment with linezolid can be considered as one of the pathogenetic mechanisms of progressive damage of peripheral nervous system in pulmonary tuberculosis patients, which must be taken into account during the course of antitubercular therapy.

Keywords: pulmonary tuberculosis, vitamin B1, vitamin B12, peripheral neuropathy.

\section{List of abbreviations}

ATT - antitubercular treatment

B1 - Thiamine

B12 - Cyanocobalamin

DR-TB - drug-resistant tuberculosis

DS-TB - drug-susceptible tuberculosis

ENMG - electroneuromyography

INH - Isoniazid

LZD - Linezolid

MNCV - motor nerve conduction velocity

PN - peripheral neuropathy

TB - tuberculosis

TML - terminal motor latency

TSL - terminal sensory latency

\section{INTRODUCTION}

Peripheral neuropathy (PN) is a condition affecting the nerves outside of the central nervous system (brain and spinal cord). It is commonly seen among tuberculosis (TB) patients. There are several causes of PN in patients with TB. Peripheral nerves can be directly affected by TB and neuropathy is attributable to peripheral nerve pressure and direct effects of the tuberculous exudates on the nerve ${ }^{1,2}$. Other factors associated with TB and PN are comorbidities. Many cases of PN are usually seen in HIV/TB co-infected patients and those who suffer from diabetes mellitus ${ }^{3-7}$. PN in patients with TB is also attributed to alcohol consumption and malnutrition, de traitement antituberculeux. Les indicateurs d'électro-neuro-myographie suivants ont également été évalués: vitesse de propagation de l'excitation motrice $(\mathrm{SRVm})$, latence motrice résiduelle (RLm), vitesse de propagation de l'excitation sensorielle (SRVm), latence sensorielle résiduelle (RLS).

Résultats. Les taux initiaux de vitamines B1 et B12 chez les patients atteints de tuberculose étaient significativement plus bas $(p=0,05)$ que dans le groupe témoin. Nous n'avons trouvé aucun changement significatif dans le niveau de vitamines et d'indicateurs de l'électro-neuro-myographie au cours du traitement par les médicaments de première intention, y compris l'isoniazide. Dans le groupe de patients ayant reçu des médicaments de deuxième intention, y compris le linézolide, nous avons constaté une diminution significative des taux plasmatiques de vitamines B1 et B12 et une détérioration de l'électro-neuro-myographie des fibres sensorielles et motrices $(p=0,05)$.

Conclusions. Par conséquent, une carence en vitamines B1 et B12 dans le traitement au linézolide peut être considérée comme l'un des mécanismes pathogéniques des lésions évolutives du système nerveux périphérique chez les patients atteints de tuberculose pulmonaire, ce qui doit être envisagé lors d'un traitement antituberculeux.

Mots-clés: tuberculose pulmonaire, vitamine B1, vitamine B12, neuropathie périphérique.

or it can develop as a consequence of antituberculosis treatment. A course of drug-susceptible tuberculosis (DS-TB) treatment usually takes 6 months. It is estimated that the incidence of $\mathrm{PN}$ rate in patients receiving the first-line antitubercular drug isoniazid (INH) is ranging from 2 to $44 \%^{8,9}$. The mechanism of action of IHN against Mycobacterium tuberculosis leads to depletion of pyridoxine (vitamin B6), and it is the loss of pyridoxine that is toxic to the nerve ${ }^{10}$. The management of drug-resistant tuberculosis (DR-TB) patients is much more complicated, as treatment course takes between 18 to 24 months and usually requires the use of multiple second-line antituberculosis agents. Linezolid (LZD) is an oxazolidinone antibacterial agent that acts by inhibiting the initiation of bacterial 
protein synthesis. Usage of LZD has increased with the emerging of highly-resistant forms of TB. This drug has attracted our attention due to its frequent administration among DR-TB patients and neurotoxic effect, with reported rates of PN from 10 to $40 \%{ }^{11,12}$. According to national standard of care, pyridoxine should be prescribed to all patients treated with LZD, though the effect of vitamin B6 supplementation on reducing LZD-associated PN has not been formally studied. The essential role of other B vitamins (B1, B12) in the development of neuropathy is also known; however, insufficient attention has been paid to the study of this issue in patients with TB.

The objective OF the STUDY was to predict the development of peripheral neuropathy by studying the changes of plasma vitamin B1 (thiamine) and vitamin B12 (cyanocobalamin) levels in patients with newly diagnosed pulmonary tuberculosis during the treatment with first- and second-line antitubercular drugs.

\section{Materials AND methods}

We examined 65 patients, new cases of pulmonary TB, who were hospitalized in Kharkiv Regional TB Dispensary No. 1, Ukraine, between 2016-2018. The excluding criteria were: extrapulmonary TB, HIV-infection, DM-comorbidity, alcohol consumption, atrophic gastritis and liver diseases. Depending on the results of drug susceptibility test, all patients were divided in two groups: group I (patients with drug-susceptible pulmonary TB), who were treated with a standard four-component scheme which included Isoniazid (INH)/ Rifampicin/ Ethambutol/ Pyrazinamide and group II (drug-resistant pulmonary TB patients), who were treated with second-line antituberculosis drugs according to the results of drug susceptibility test, but each regimen included LZD and did not contain INH. Twenty matched control patients were included for baseline assessment comparison. Plasma vitamin B1 (thiamine) and plasma vitamin B12 (cyanocobalamin) levels were studied in all patients before treatment and after 30 days of antituberculosis therapy. Informed consent was obtained from all the patients included in the study.

All patients were examined by neurologist and concomitant peripheral neuropathy was excluded. To identify changes of the peripheral nervous system, we performed stimulation electroneuromyography (ENMG) on the lower limbs. We evaluated function of $n$. tibialis - m. abductor hallucis (area of the arch of the foot, stimulation at the level of the tarsus and popliteal fossa) and n. peroneus - m.extensor digitorum brevis (area of the outer edge of the dorsum of the foot, stimulation at the level of the tarsus and popliteal fossa). In order to assess the parameters of motor and sensory conductivity, the following factors were evaluated: motor nerve conduction velocity (MNCV), terminal motor latency (TML), sensory nerve conduction velocity (SNCV) and terminal sensory latency (TSL).

Statistical processing of the obtained results was carried out by analyzing the contingency tables using the Statistica Basic Academic 13 for Windows software package. We used the median $(\mathrm{Me})$ interquartile range (Lower - lower quartile, Upper - upper quartile) and sample size (min - minimum, max maximum value). To determine the differences between groups, non-parametric statistics for unbound samples were used - Mann-Whitney (CMU) and Wilcoxon's criteria (CW) for related samples (dynamic observation).

The work was performed according to the requirements for researches with the participation of people: Statute of the Ukrainian Association for Bioethics and the GCP norms (1992), requirements and norms of ICH GLP (2002), typical ethics provisions of the Ministry of Public Health of Ukraine 66 dated February 13, 2006.

\section{Results}

Seventeen patients were excluded from the study because during their examination concomitant diseases (HIV-infection, DM, hepatitis, atrophic gastritis) or alcohol consumption were revealed. Thus, the study was performed on 48 patients aged $18-55$ years (39 men $(81.25 \%)$ and 9 women (18.75\%)). Group I consisted of 22 drug-susceptible TB (DS-TB) patients, group II - 26 drug-resistant TB (DR-TB) patients.

The baseline level of vitamin B1 in TB patients ranged from 17.18 to $43.27 \mathrm{nmol} / \mathrm{L}$ and the median level was $27.84 \mathrm{nmol} / \mathrm{L}$, significantly lower $(\mathrm{p}<0.05)$ compared to controls - $56.45 \mathrm{nmol} / \mathrm{L}$ (min 40.92, $\max 71.44 \mathrm{nmol} / \mathrm{L}$ ). The same tendency we found when we compared vitamin B12 indices: the median level of vitamin B12 in TB patients was 0.20 $\mathrm{nmol} / \mathrm{L}$ ( $\min 0.12$, $\max 0.61$ ), while the median level of vitamin B12 in healthy persons was $0.28 \mathrm{nmol} / \mathrm{L}$ ( $\min 0.17$, $\max 0.38$ ). The difference between baseline levels of vitamin B12 was statistically significant $(\mathrm{p}<0.05)$ (Table 1).

When comparing the median values of vitamin B1 indices between the groups of DS-TB and DR-TB patients we didn't find any statistical significance, though it was higher in DR-TB patients (28.37 nmol/L vs $27.48 \mathrm{nmol} / \mathrm{L})$. We did not find any statistical changes in vitamin $B$ status of DS-TB patients during the 30 days of treatment with INH. 
Table 1. Baseline vitamin B status and ENMG-indices of TB group and control group

\begin{tabular}{|c|c|c|c|c|c|c|c|}
\hline & Mean & Median & Minimum & Maximum & $\begin{array}{l}\text { Lower - } \\
\text { Quartile }\end{array}$ & $\begin{array}{l}\text { Upper - } \\
\text { Quartile }\end{array}$ & Std.Dev \\
\hline \multicolumn{8}{|c|}{ Control group $(n=20)$} \\
\hline $\mathrm{B} 1(\mathrm{nmol} / \mathrm{L})$ & 56.37 & 56.45 & 40.92 & 71.45 & 48.92 & 66.27 & 9.21 \\
\hline $\mathrm{B} 12$ (nmol/L) & 0.29 & 0.29 & 0.18 & 0.38 & 0.24 & 0.36 & 0.06 \\
\hline $\operatorname{MNCV}(\mathrm{m} / \mathrm{s})$ & 60.87 & 60.1 & 53.9 & 68.5 & 58.54 & 63.75 & 3.97 \\
\hline TML (ms) & 1.84 & 1.8 & 1 & 2.6 & 1.5 & 2.05 & 0.45 \\
\hline $\operatorname{SNCV}(\mathrm{m} / \mathrm{s})$ & 57.22 & 59.5 & 45 & 66.8 & 50 & 63 & 7.04 \\
\hline TSL (ms) & 1.71 & 1.89 & 1 & 2.5 & 1.25 & 2.1 & 0.46 \\
\hline \multicolumn{8}{|c|}{ TB patients $(n=48)$} \\
\hline $\mathrm{B} 1$ (nmol/L) & 28.51 & 27.85 & 17.18 & 43.27 & 24.21 & 32.59 & 6.08 \\
\hline $\mathrm{B} 12(\mathrm{nmol} / \mathrm{L})$ & 0.22 & 0.20 & 0.12 & 0.61 & 0.18 & 0.24 & 0.07 \\
\hline $\operatorname{MNCV}(\mathrm{m} / \mathrm{s})$ & 52.94 & 51 & 45 & 66 & 50 & 55.9 & 4.79 \\
\hline TML (ms) & 2.35 & 2.33 & 1.3 & 3.7 & 1.98 & 2.67 & 0.45 \\
\hline $\operatorname{SNCV}(\mathrm{m} / \mathrm{s})$ & 44.79 & 43.7 & 37 & 59 & 42 & 46.8 & 4.14 \\
\hline TSL (ms) & 2.368 & 2.4 & 1.5 & 4.8 & 2.05 & 2.65 & 0.53 \\
\hline
\end{tabular}

On the contrary, in DR-TB patients, the median level of vitamin B1 decreased during 30 days of antitubercular treatment (ATT) $(33.0 \mathrm{nmol} / \mathrm{L}$ vs 30.5 $\mathrm{nmol} / \mathrm{L}$ ), though changes were not statistically significant. Also, we found a significant $(p<0.05)$ decrease in plasma B12 median level in DR-TB patients who were treated with LZD $(0.24 \mathrm{nmol} / \mathrm{L}$ vs $0.16 \mathrm{nmol} / \mathrm{L})$ (Fig.1).

ENMG allowed us to identify structural and functional disorders in the peripheral nerves of the lower limbs, with the involvement of their both sensory and motor fibers. However, regardless of the type of ATT used, more significant changes in all examined patients were detected by sensory fibers. It should be noted that ENMG changes were detected in all TB patients prior to treatment (Table 1). We registered slowing of SNCV to $43.7 \mathrm{~m} / \mathrm{s}$ (in control group $59.5 \mathrm{~m} / \mathrm{s}$ ) combined with prolonged TSL to $2.4 \mathrm{~ms}$ (in control group $1.89 \mathrm{~ms}$ ). Similar, but less pronounced changes were recorded for motor fibers - slowing of MNCV to $51 \mathrm{~m} / \mathrm{s}$ (in control group $60.1 \mathrm{~m} / \mathrm{s}$ ) combined with prolonged TML to $2.33 \mathrm{~ms}$ (in control group $1.8 \mathrm{~ms}$ ). These changes confirm the involvement of peripheral nerves in the pathological process, possibly as a result of the development of general tuberculous intoxication. After 30 days of ATT we did not find any significant changes of ENMG in the group of patients receiving INH, compared to similar indicators before treatment. At the same time, in the group of patients treated with LZD, all the studied parameters were significantly worsened: SNCV $35.87 \mathrm{~m} / \mathrm{s}$, TSL $2.98 \mathrm{~ms}$, MNCV $\mathrm{m} / \mathrm{s} 45.5$, TML $4 \mathrm{~ms}$ (Fig. 2-5). It should be noted that slowing of nerve conduction velocity combined with prolonged terminal latency in TB patients, demonstrated the demyelinating nature of peripheral nervous system (PNS) lesion. Thus, the damage of PNS is a consequence of the presence of the underlying disease, as well as the use of a certain type of therapy. When comparing the obtained ENMG changes with plasma vitamin B1 and B12 level, certain regularity was observed. The patients treated with LZD had progressive worsening of ENMG parameters, which were combined with a decrease in the plasma levels of vitamins B1 and B12, while in those treated with INH, both ENMG parameters and plasma vitamins $B$ levels did not significantly change.

\section{Discussion}

Linezolid is an effective synthetic oxazolidinone antibiotic, widely used in the treatment of drug-resistant TB. However, long-term administration of linezolid causes serious adverse effects in almost $60 \%$ of the cases ${ }^{13}$. The most frequent adverse effects are: thrombocytopenia, irreversible peripheral neuropathy, optic neuropathy ${ }^{13}$.

A deficiency of vitamins involved in the immunity can cause the weakening of the immune system, which in turn will lead to the development of infectious diseases, including tuberculosis ${ }^{14,15}$. In a cross-sectional study performed in Ethiopia, the concentration of vitamin $\mathrm{C}$, vitamin $\mathrm{E}$, and vitamin $\mathrm{A}$ was found to be lower in TB patients as compared to healthy controls and decreased vitamin $\mathrm{D}$ levels were 
Box \& Whisker Plot

Include condition: $\mathrm{v} 11=1 \& \mathrm{v} 1=1$

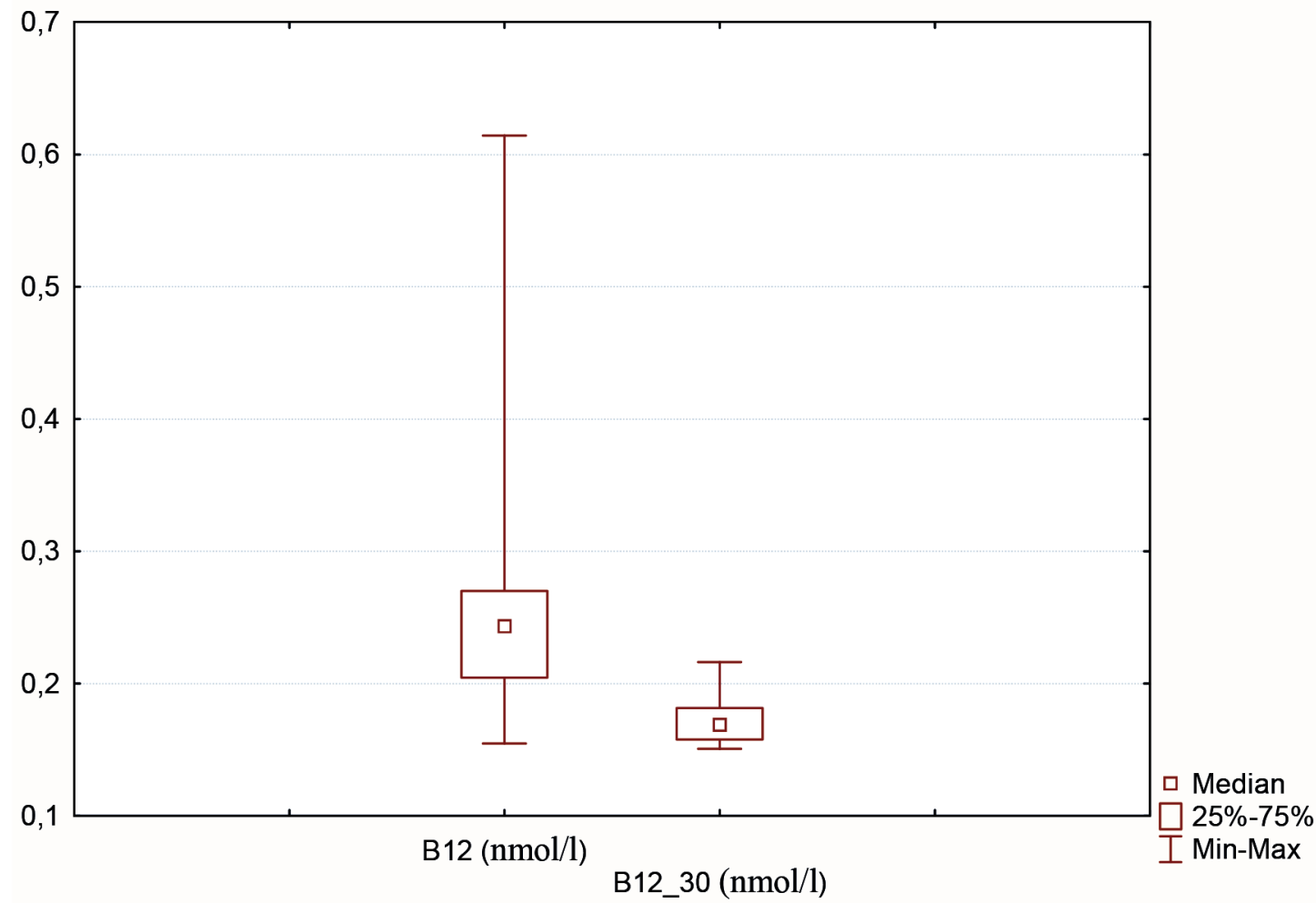

Figure 1. Dynamics of plasma vitamin B12 levels (nmol/L) prior to treatment and after 30 days of therapy with Linezolid $(p=0.0019, \mathrm{CW})$

Box \& Whisker Plot

Include condition: v11=1 \& v1=1

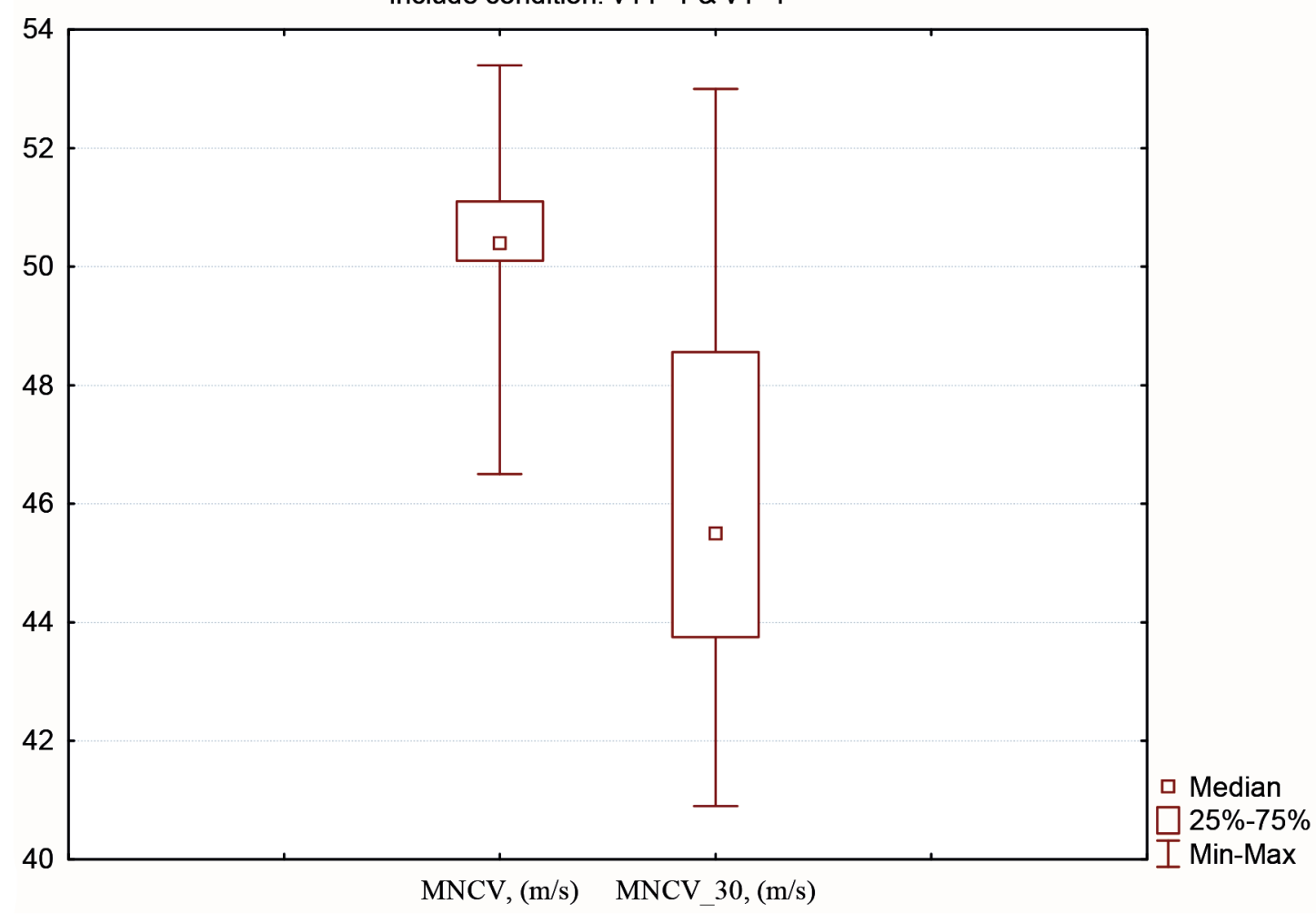

Figure 2. Dynamics of motor nerve conduction velocity $(\mathrm{m} / \mathrm{s})$ prior to treatment and after 30 days of therapy with Linezolid $(p=0.001, C W)$ 
Box \& Whisker Plot

Include condition: v11=1 \& v1=1

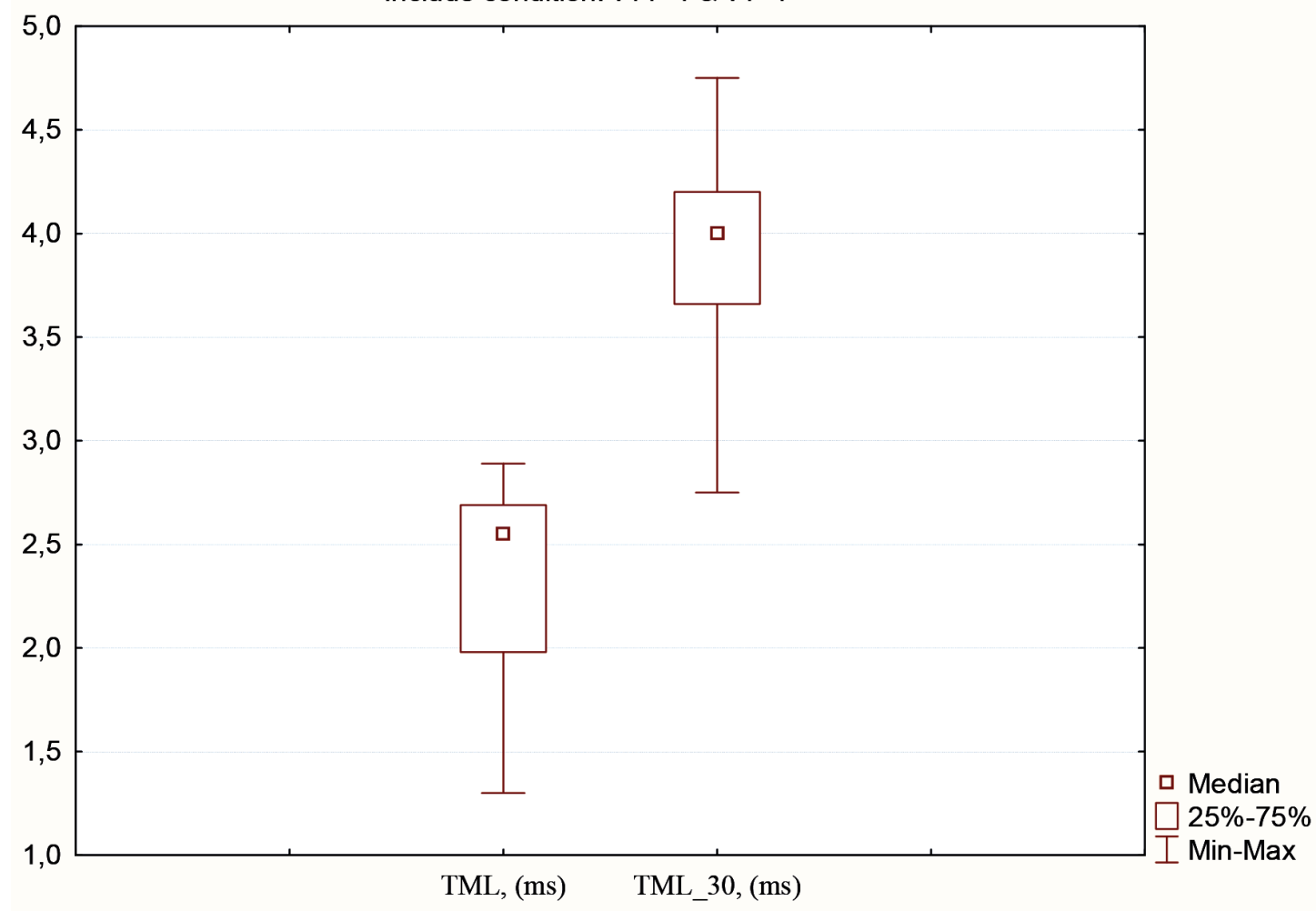

Figure 3. Dynamics of terminal motor latency $(\mathrm{ms})$ prior to treatment and after 30 days of therapy with Linezolid $(p=0.00029, \mathrm{CW})$

Box \& Whisker Plot

Include condition: $\mathrm{v} 11=1 \& \mathrm{v} 1=1$

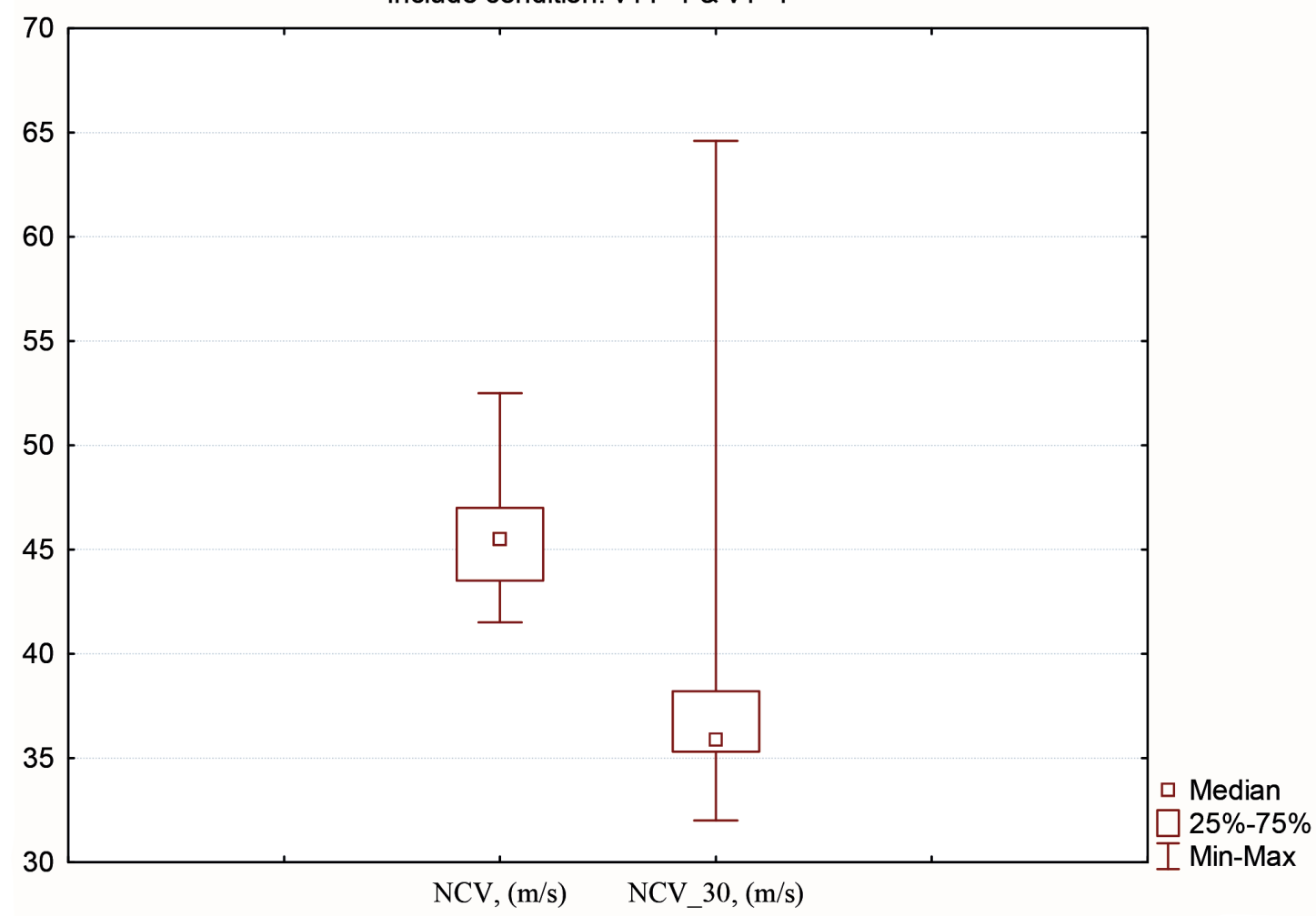

Figure 4. Dynamics of sensory nerve conduction velocity $(\mathrm{m} / \mathrm{s})$ prior to treatment and after 30 days of therapy with Linezolid $(p=0.0056, \mathrm{CW})$ 
Box \& Whisker Plot

Include condition: $v 11=1 \& v 1=1$

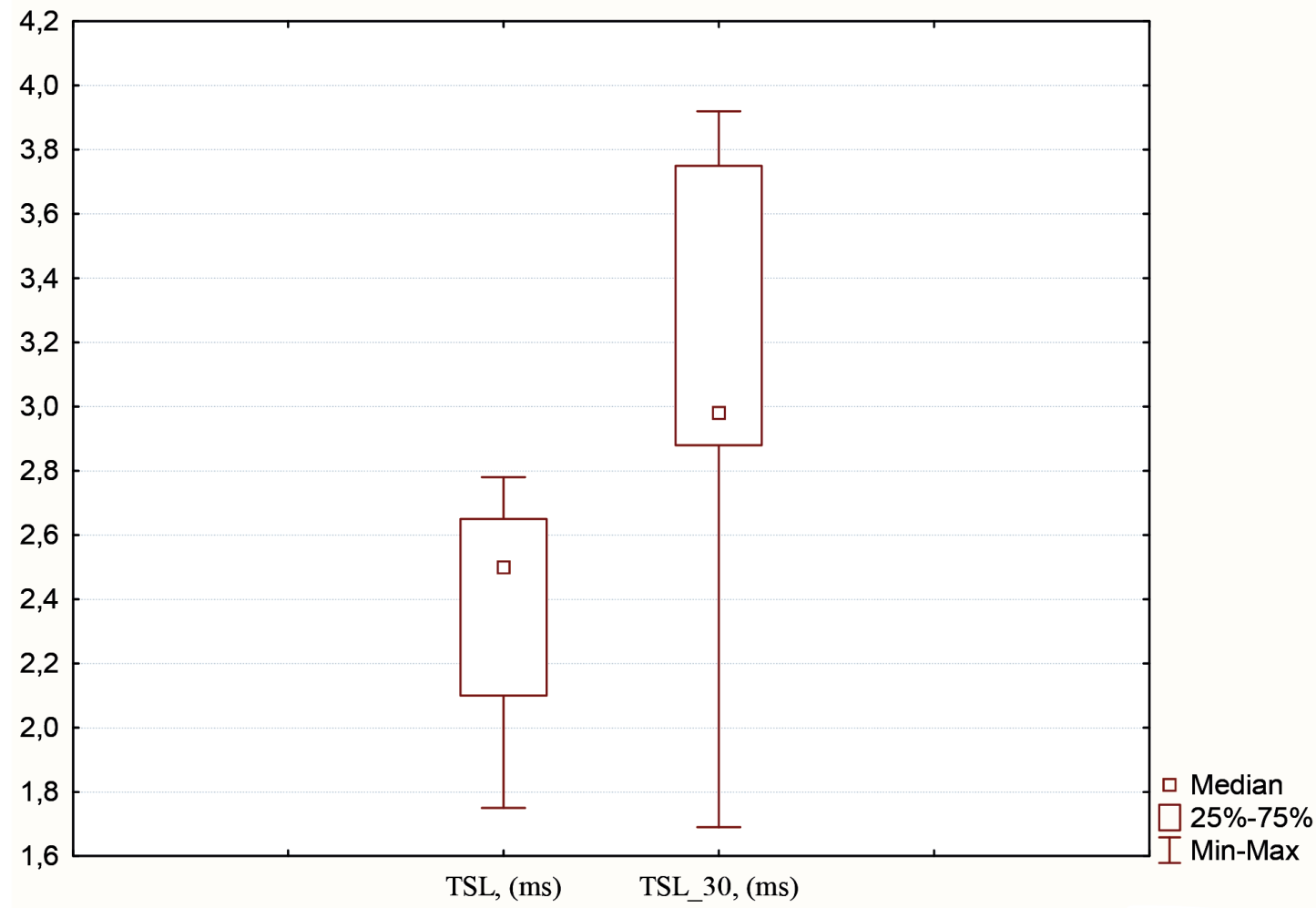

Figure 5. Dynamics of terminal sensory latency (ms) prior to treatment and after 30 days of therapy with Linezolid $(p=0.0041, C W))$

associated with a 5-fold increased risk for progression to $\mathrm{TB}^{16}$.

Based on the fact that the deficiency of vitamins B family may be a cause of PN development, we decided to investigate the initial plasma levels of vitamins B1 and B12 in patients with newly diagnosed pulmonary $\mathrm{TB}$ and evaluate the dynamics of vitamin $B$ status during the treatment with IHN or LZD. In our study, we found that TB patients had significantly lower initial levels of vitamin B1 and B12 compared to control group. Moreover, plasma levels of vitamins B1 and B12 significantly decreased in newly diagnosed pulmonary TB patients, after 30 days of treatment with combinations of LZD and second-line anti-TB drugs. Along with a decrease of plasma vitamin B1 and B12 levels, in the group of patients who were treated with LZD, there was also a statistically significant worsening of ENMG by sensory and motor fibers.

\section{Conclusions}

Our results suggest that newly diagnosed pulmonary tuberculosis patients have lowered initial plasma levels of vitamins B1 and B12, compared to age- and sex-matched healthy persons. We did not find significant changes in vitamin B status and electroneuromyography during the treatment with combinations of isoniazid and first-line anti-TB drugs. During the treatment with combinations of linezolid and second-line anti-TB drugs, we identified a significant decrease of plasma levels of vitamins B1 and B12 and worsening of electroneuromyography indices by sensory and motor fibers. Consequently, the deficiency of vitamins B1 and B12 during treatment with linezolid can be considered as one of the pathogenetic mechanisms of progressive damage of peripheral nervous system in pulmonary tuberculosis patients, which must be taken into account during the course of antitubercular therapy.

\section{Author contributions}

Conceptualization: O.M.S., O.S.S., and L.D.T.; Methodology: O.M.S., O.S.S., and O.L.T.; Software: O.M.S. and I.V.Y.; Validation: O.I.D. and O.L.T.; Formal analysis: O.M.S., O.I.D.; Investigation: O.M.S., O.S.S., and I.V.Y.; Resources: O.M.S., O.L.T.; Data curation: O.M.S., O.S.S., L.D.T., I.Y.M., I.V.Y., O.I.D., and O.L.T.; Writing - original draft preparation: O.M.S., O.S.S., and L.D.T.; Writing - review and editing: M.M.O., O.S.S., and I.Y.M.; Visualization: O.M.S. and O.L.T.; Supervision: 
O.S.S. and M.M.O.; Project administration: L.D.T. All the authors have read and agreed with the final version of the article.

\section{Compliance with Ethics Requirements:}

„The authors declare no conflict of interest regarding this article"

"The work was performed according to the requirements for researches with the participation of people: in accordance with Articles 28, 49 and 52 of the Constitution of Ukraine, Articles 6, 7 and 8 of the Law of Ukraine "On Medicines", taking into account the norms applicable in international practice, ethical standards in the Helsinki Declaration (1964-2013), Council of Europe Convention of Human Rights and Biomedicine (1997), EU Directives EU Directives 2010/63 "On the protection of animals, it is used for scientific purposes", orders of the Ministry of Health of Ukraine No 249, 01.03.2012. Statute of the Ukrainian Association of Bioethics and Norms GCP (1992), requirements and norms ICH GLP (2002). The work is approved by the Ethics Commission of Kharkiv National Medical University (protocol No. 2 dated 02/03/2016 - MD, Professor Ospanova T.S. (+ 38050 9988242)) and Higher State Educational Establishment of Ukraine "Bukovinian State Medical University" (protocol No. 4 dated 18/12/2014); head - Doctor of Medical Sciences, Professor Zamorskyi I.I. (+ 38 0685512268)). Informed consent was obtained from all the patients included in the study"

"No funding for this study"

\section{Acknowledgments: none}

\section{References}

1. Poulose SP, Sugath S, Gopalkrishnan KC. Tuberculosis affecting the median nerve. Kerala J Orthop. 2011;24:43-45.

2. Warpe BM, Poflee SV, Pande NP, Shrikhande AV. Tuberculous neuritis: a rare sequel of a common disease. Indian J Pathol Microbiol. 2014;57(1):69-71.
3. Saylor D, Nakigozi G, Nakasujja N, et al. Peripheral neuropathy in HIV-infected and uninfected patients in Rakai, Uganda. Neurology. 2017;89(5):485-491.

4. Cherry CL, Wadley AL, Kamerman PR. Diagnosing and treating HIV-associated sensory neuropathy: a global perspective. Pain Manag. 2016;6(2):191-199.

5. Ziegler D, Papanas N, Vinik AI, Shaw JE. Epidemiology of polyneuropathy in diabetes and prediabetes. Handb Clin Neurol. 2014;126:3-22.

6. Pafili K, Papanas N, Ziegler D. Neuropathy in diabetes: "one cannot begin it too soon". Angiology. 2018;69(9):752-754.

7. Shevchenko OS, Todoriko LD, Ovcharenko IA, et al. Dynamics of aldosterone, connective tissue reorganization and glucose level as markers for tuberculosis treatment effectiveness. Arch Balk Med Union. 2019;54(2):274-280.

8. Marks DJ, Dheda K, Dawson R, Ainslie G, Miller RF. Adverse events to antituberculosis therapy: influence of HIV and antiretroviral drugs. Int J STD AIDS. 2009;20:339-345.

9. Stettner M, Steinberger D, Hartmann CJ, et al. Isoniazid-induced polyneuropathy in a tuberculosis patient implication for individual risk stratification with genotyping? Brain Behav. 2015;5(8):e00326.

10. Van der Watt JJ, Benatar MG, Harrison TB, Carrara H, Heckmann JM. Isoniazid exposure and pyridoxine levels in human immunodeficiency virus associated distal sensory neuropathy. Int J Tuberc Lung Dis. 2015; 19(11):1312-1319.

11. Kishor K, Dhasmana N, Kamble SS, Sahu RK. Linezolid-induced adverse drug reactions - an update. Curr Drug Metab. 2015;16(7):553-559.

12. Bobylev I, Maru H, Joshi AR, Lehmann HC. Toxicity to sensory neurons and Schwann cells in experimental linezolid-induced peripheral neuropathy. J Antimicrob Chemother. 2016;71(3):685-691.

13. Swaminathan A, du Cros P, Seddon JA, Mirgayosieva S, Asladdin R, Dusmatova Z. Peripheral neuropathy in a diabetic child treated with linezolid for multidrug-resistant tuberculosis: a case report and review of the literature. BMC Infect Dis. 2017;17(1):417.

14. Diaconu C, Balaceanu A, Morosan E. Sepsis biomarkers: past, present and future. Farmacia. 2015;63(6):811-815.

15. Diaconu C, Paraschiv B. Clinical characteristics of obese patients with hypertension and chronic ischemic heart disease. Romanian Journal of Internal Medicine. 2014;52(4):251-255.

16. Talat N, Perry S, Parsonnet J, Dawood G, Hussain R. Vitamin D deficiency and tuberculosis progression. Emerg Infect Dis. 2010;16(5): 853-855. 